\title{
Indication and outcome of adult liver transplantation for post-Kasai biliary atresia
}

\author{
Shin Hwang, Jung-Man Namgoong, Chul-Soo Ahn, Deok-Bog Moon, Tae-Yong Ha, Gi-Won Song, Dong-Hwan Jung,
}

Gil-Chun Park, Kyung Mo Kim, Sung-Gyu Lee

Department of Surgery, Asan Medical Center, University of Ulsan College of Medicine, Seoul, Korea

Background: Some young adults who underwent Kasai portoenterostomy (KPE) for biliary atresia (BA) can live for long period with native liver, but a considerable proportion of patients require liver transplantation (LT). This study was intended to analyze the indications and outcomes of LT in young adult LT recipients who had survived long period with native liver after KPE.

Methods: We selected seven patients who were 18 years or older at the time of LT operation out of 116 BA patients who underwent primary LT from 2008 to 2019.

Results: The mean ages at KPE and LT were $2.1 \pm 0.9$ months and $22.0 \pm 5.1$ years, respectively. Mean serum total bilirubin level and model for end-stage liver disease score at $L T$ was $7.91 \pm 7.22 \mathrm{mg} / \mathrm{dL}$ and $15.3 \pm 6.0$, respectively. The main reasons for $L T$ were liver cirrhosis and/or portal hypertension-associated complications in five and intractable cholangitis in two. Types of LT were living donor $\mathrm{LT}$ in five and deceased donor $\mathrm{LT}$ in two. All seven patients are currently alive during the mean follow-up period of $74.7 \pm 40.9$ months. One patient suffered from outflow graft vein obstruction requiring endovascular stenting. One patient showed core antibody-positivity-induced de novo hepatitis B virus infection, which was well managed with antiviral therapy.

Conclusions: Young adult patients with BA are a unique group of patients requiring specialist care regarding transition from pediatric to adult services. The outcome of LT in young adult BA patients were excellent, thus LT should be considered in patients showing serious BA-associated complications.

Corresponding author: Shin Hwang

E-mail: shwang@amc.seoul.kr

(c) The Korean Society for Transplantation

This is an Open Access article distributed under the terms of the Creative Commons Attribution Non-Commercial License (http://creativecommons.org/licenses/by-nc/4.0/) which permits unrestricted non-commercial use, distribution, and reproduction in any medium, provided the original work is properly cited. 